\title{
EL ASUNTO DEL «FUNDAMENTO» PARA LOS DERECHOS HUMANOS: ¡PSEUDOPROBLEMA! \\ (O bien, cuestión de unas elucidaciones cuasiteológicas)
}

\author{
Enrique P. Haba \\ Universidad de Costa Rica
}

\begin{abstract}
RESUMEN. El autor se propone demostrar que la pregunta por el fundamento de los derechos humanos no es una cuestión relevante, ni en el aspecto práctico ni en el teorético. Para ello, recorre los planos del ejercicio, el estrictamente teórico y el metafísico, donde éste se presenta. En el primero, advierte que la cuestión no suele plantearse, por lo que las discusiones sobre el fundamento de los derechos humanos no tienen relevancia práctica. En el segundo, la pregunta por tales fundamentos, sea porque encubre cuestiones empíricas propias de las ciencias sociales o porque señala estructuras del pensamiento, no se presenta como necesaria o habitual. Y, en el plano metafísico, la pregunta supondría reconocer dichos fundamentos como postulados de fe, propios de pensamientos teológicos.
\end{abstract}

ABstract. The author seeks to demonstrate that the question with respect to the grounds for human rights is not a relevant one, neither in its practical nor in its theoretical sense. In order to do so, he explores the levels of the exercising of these rights, the strictly theoretical level and the metaphysical level, where it appears. In the first level, he points out that the question is not usually raised, which is why discussions on the grounds for human rights have no practical relevance. In the second level, the question with respect to these grounds, whether because it masks empirical questions characteristic of the social sciences or because it makes reference to structures of thought, is a question which does not appear as either necessary or usual. And, on the metaphysical level, the question would mean recognising these grounds as postulates of faith, which belong to theological thought. 
Para la preservación de esos derechos no es tampoco muy importante proveerlos de unas pseudofundamentaciones, fácilmente refutables; mucho más fundamental es reconocer, y en lo posible conservar, el conjunto de las condiciones sociales bajo las que aquellos resultan posibles $y$ eficaces.

Topitsch $^{1}$

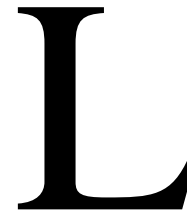

as elucidaciones sobre el «fundamento» de lo que sea comprendido bajo el membrete derechos humanos (DH) son tema favorito en libros, artículos, conferencias, congresos. Llama la atención que se siga produciendo tanta literatura al respecto, máxime teniendo en cuenta que la precisión decisiva sobre ese punto fue hecha -y es bastante conocida- hace muchos años ya:

«Hoy el problema de fondo relativo a los derechos humanos es no tanto lo de justificarlos, sino cómo protegerlos. No es un problema filosófico, sino político» ${ }^{2}$.

Esa observación no puede ser más pertinente, sin duda, por lo que hace al plano práctico. Empero, a decir verdad, ella por sí sola no basta para responder a la cuestión teorética de saber si no será cierto que estos derechos tienen, después de todo, tales o cuales fundamentos, así sea implícitamente. Pudiera ser que los fundamentos en cuestión estén obrando efectivamente, más allá de que sus locutores discursos tengan o no conciencia clara sobre ello. Tal vez podría tratarse de unas condiciones transcendentales (en sentido kantiano) o de cualquier modo básico-estructurales, que acaso «están ahí» como requisito sine qua non del pensamiento que comanda la entrada en juego de dichos derechos. Este punto específico, no resuelto mediante la aguda observación de Bobbio, es el que me propongo examinar a continuación. Mi tesis es que ni siquiera en ese plano, de alcance meramente teorético, la cuestión del «fundamento» merece que se dilapide tiempo en elucidarla. Me explicaré3.

${ }^{1}$ E. Topitsch, Sozialphilosophie zwischen Ideologie und Wissenschaft, Neuwied y Berlín, 1971: 95 (trad. E.P.H.); el énfasis mediante negritas fue añadido aquí.

${ }^{2}$ N. Bobbio, El problema de la guerra y las vías de la paz, Barcelona 1982: 128 [trad. corregida aquí]. Recuérdese la categórica observación que ya Topitsch había formulado anteriormente [supra: nota 1].

${ }^{3}$ Puede verse también mi ensayo «¿De qué viven los que hablan de derechos humanos (tres tipos de discursos-DH: ‘de’, ‘para’, ‘con’)» [Doxa-26 (2003), pp. 869-885] y los resúmenes que he reunido bajo el título: «En torno a las formas de discursear sobre el talismán 'derechos humanos' (Un compendio de observaciones con respecto a maneras de decir mucho y no decir nada)» [en Roque Carrión Wam (editor, compilador), Derechos humanos/Direitos humanos. (De las diversas maneras de atraer a los hombres al conocimiento y crítica de sus derechos humanos), Centro Latinoamericano de Investigaciones Jurídicas y Sociales (CELIJS), 
El término fundamento aparece utilizado ya sea en sentidos muy amplios o según otros mucho más estrictos, en tales o cuales contextos discursivos. En ambos casos suele hacer referencia, grosso modo, a algo así como lo siguiente: al sostener que cierto $\mathrm{X}$ constituye un o el «fundamento» de $\mathrm{Z}$, se entiende que para poder darse $\mathrm{Z}$ (propiamente) es indispensable que también $\mathrm{X}$ «esté ahí», sea previa o concomitantemente. Ahora bien, tanto Z como X pueden consistir: a) ya sea en unos fenómenos empíricos (acontecimientos fácticos, leyes de la naturaleza o regularidades sociales); b) o bien, tratarse de unos elementos discursivos (ideas, conceptos, valoraciones, estructuras lógicas); o también, c) hasta puede que la palabreja se traiga al tapete para encarar unos datos metafísicos (Voluntad Divina, esencias o «naturaleza»). Estos tres planos de enfoques caben, por supuesto, también sobre cuestiones de la temática DH.

Plano (a).- Si es cuestión de investigar propiamente esto, empiria, la palabra «fundamento» puede ser sustituida con ventaja de claridad -para evitar confusiones con lo propio de los otros dos planos- por la terminología que se usa en el discurso técnico de las ciencias sociales. En tal caso corresponde hablar, simplemente, de: leyes u otras correlaciones fácticas, causas necesarias o suficientes, cuadros estadísticos y otras comprobaciones de probabilidad, en niveles de lo estudiado por la Psicología o la Sociología.

No veo qué pueda valer la pena señalar como «fundamentos» (en el sentido apuntado) de unos «derechos humanos», si ello no ha de consistir en conocimientos proporcionados por las ciencias sociales mismas. Se trata ni más ni menos que de ciertas comprobaciones, reales o supuestas, acerca de comportamientos empíricos consistentes en las conductas humanas que se incluyan en al área definida mediante aquella denominación; definición convencional, como en toda formulación lingüística. Ahora bien: ni el jurista, ni el filósofo, ni quienes escriben sobre Teoría (básica, epistemología) del Derecho en general, ninguno de ellos dispone de conocimientos especializados propios para decir gran cosa sobre tales respectos. En todo caso, aquellos pueden proponer alguna definición estipulativa de esos derechos, como punto convencional de partida, simplemente con vistas a delimitar un objeto específico de estudio para investigaciones empíricas sobre la materia; mas estas investigaciones mismas serán encomendadas a otros, a científicos sociales.

Solo los propios científicos sociales están en condiciones de investigar en serio, esto es, valiéndose para ello de su instrumental técnico profesional,

Facultad de Derecho-Universidad de Carabobo, Valencia, Venezuela (libro que será publicado próximamente). 
dichos aspectos: qué ingredientes de la realidad social y de la mente humana ejercen (¡o no!) tales o cuales influencias, de hecho, para que la gente llegue a creer y a actuar en función de ciertos cuerpos de ideas llamados DH. Los «fundamentos» de estos derechos no podrían ser, en tal sentido, sino unas características empírico-antropológicas u otras que son contingentemente empírico-sociales, de los comportamientos humanos respectivos. No es probable que los científicos mismos quieran acudir, tampoco para estudiar tales cuestiones, a una categoría del pensamiento tan propicia a sustentar confusiones, por lo vaga y emocionalizante, como es la palabra «fundamentos».

Plano (b).- Esta cuestión remite a la lógica del discurso práctico. Entonces el término «fundamento» necesita recuperar su significado más propio, el sentido estricto de esa palabra. De acuerdo con este sentido, la tesis $X$ es fundamento de la tesis $\mathrm{Z}$, cuando es imposible que $\mathrm{Z}$ sea aceptado por el pensamiento -salvo contradiciéndose- si no se parte de aceptar asimismo $\mathrm{X}$. Ahora bien, tal «imposible» puede referirse a dos ítems muy distintos: (i) hay imposibilidades de carácter estrictamente lógico; con independencia de eso existen, por otro lado, (ii) posibilidades e imposibilidades de naturaleza empírico-intelectual. Muy a menudo las segundas no coinciden con las primeras. No necesariamente lo inadmisible si nos ubicamos en (i), es imposible hallarlo, en la práctica, formando parte de ciertos discursos paralelos del tipo (ii), y viceversa. Es muy común que una persona se contradiga sin darse cuenta de ello: así, en la esfera (ii) se hace posible lo que resulta imposible en (i). Sobre todo, tanto lo que es posible como lo que no lo es en (i), puede resultar por completo indiferente, ni siquiera ser tomado en cuenta, en numerosos planos reales de pensamientos cultivados por la gente; también es así hasta en los discursos profesionales de los juristas. Pues bien, sostengo que no menos en cuanto a lo puramente lógico (i) que para las prácticas discursivas en general (ii), los DH no necesitan, ni suele ser presentado, fundamento discursivo alguno para reconocerle a esos derechos su calidad de tales.

(i) En el plano lógico, los axiomas de cualquier razonamiento son, como se sabe, simplemente postulados en esa calidad. Pueden ser unos u otros, según el tipo de discurso y las preferencias del locutor. Todo razonamiento se asienta en tales o cuales tesis de base, llámeseles axiomas o fundamentos: son el punto donde el locutor, en un hipotético regreso desde la o las conclusiones hasta la o las premisas iniciales (dicho punto), considere suficiente detenerse, no preguntar «más allá». Tanto unos DH -sean estos lo que fueren- como otras ideas pueden señalarse, en su caso, a título de fundamento en un discurso. Así ubicadas no hay ninguna necesidad lógica de pedir a su vez un fundamento para esos derechos en sí mismos. Desde 
luego, tampoco existe impedimento lógico de imputarles aun a estos mismos algún o algunos fundamentos que se consideren estar más en profundidad, si hay quienes sientan la necesidad psicológica de hacer retroceder aún la cadena -virtualmente inagotable- de los fundamentos, y de los fundamentos de fundamentos, más allá del punto normal de partida en la materia. Pedir o no tales fundamentos es contingente, no depende sino de las preferencias mentales de quienes manejen los discursos en cuestión. Se trata apenas de ciertos «gustos» intelectuales al respecto. Claro que un «gusto» puede, a su vez, ser objeto de justificaciones. Mas estas justificaciones, sean cuales fueren, en sí mismas no responden a ninguna necesidad lógica que las haga indispensables para poder efectuar aquel discurso, ni constituyen forzosamente parte -ni siquiera en forma implícita- del propio contenido de este. De ahí, que también el discurso-DH puede perfectamente bien prescindir, y así se hace casi siempre, de remitirse a fundamentos. Igualmente pasa con tantos otros tipos de discursos, científicos o no: para reconocer y para manejar las nociones que en ellos mismos funcionan como básicas, nadie necesita preocuparse por averiguar si tienen o no tienen unos pretendidos «fundamentos».

(ii) Tampoco se echa de ver ninguna necesidad de orden psicológicointelectual, que se haga presente en la dinámica propia de los pensamientos reales que mueven a las personas de carne y hueso -políticos, juristas, gente en general- cuando hablan de «derechos humanos», por la cual los protagonistas de esos discursos hubieran de ponerse a buscar, y muchísimo menos esas personas son efectivamente movidas por, unos «fundamentos» para estos derechos. Los individuos simplemente creen, o no, en tales derechos, dogmáticamente. Ni más ni menos que como las gentes creen -isin que se les ocurra preguntar por qué!- en ciertas ideas enfatizadas por tal o cual ideología, en la religión que aprendieron de niños y otras preconcepciones. No representa mucho más que una fantasía narcisista de cierto mundillo académico, lo de presuponer que las doctrinas sociales se mueven en virtud de unos «fundamentos» que están más allá de los dogmas mismos proclamados por ellas. El pensamiento real que produce los discursos-DH no se preocupa por, ni presupone, ningún «fundamento» para afirmar tales derechos. Simplemente, los entiende como válidos en sí mismos y por sí mismos.

Plano (c).- Si de lo que se trata, es de remitirse a unas postulaciones metafísicas, estas pueden consistir en tesis de lo más variadas, y eventualmente se contraponen unas a otras. Son o no son creíbles según cuál sea la fe de cada quien. Que estas creencias correspondan o no a Algo verdadero, no hay manera de dilucidarlo científicamente ni, en general, por cualesquiera medios propiamente racionales. Las afirmaciones sobre ese Algo no están 
en condiciones de sustentarse en vías del pensamiento laicas y sometidas a controles de general intersubjetividad. Sean o no ciertos (¡vaya uno a saber!) tales «fundamentos» con respecto a los DH, no son ni pueden ser sino unas proposiciones subjetivo-valorativas, aunque a menudo se presentan camufladas bajo una terminología pseudoobjetivante, la cual por añadidura suele ser no menos vaga que ampulosa. Se afirma, por ejemplo, que hay unas verdades «ontológicas» o «absolutas» -palabrejas que funcionan como expediente de inmunización contra toda posible puesta en duda- reconocibles sin más: así, la «eminente dignidad» de toda persona humana, su «naturaleza» propia en cuanto «hijos» de Dios (hechos «a imagen y semejanza» del Creador). Enunciados de ese género no son susceptibles de verdadera discusión, pues dan previamente por intocables unos pre-juicios fundamentales, así como a priori son ubicados por encima de toda posibilidad de falsación obtenible mediante contrastaciones empíricas. Constituyen un capítulo centrado en juegos de lenguaje cuya gramática responde ante todo y sobre todo a patrones de carácter dogmático-emocional. Su problemática, si es que puede calificarse de tal, provoca elucidaciones que son, básicamente, de orden teológico o parateológico, así como da motivo a ensayos en unas cacomúsicas-de-palabras como los cultivados por el pensamiento «hermenéutico» (tipo Heidegger o Apel-Habermas) y otras ampulosas jerigonzas (p. ej., Derrida).

Síntesis.- 1) En cuanto al ejercicio mismo de los DH, la pregunta por unos eventuales «fundamentos» para ellos no suele plantearse; las discusiones al respecto -académico-celestiales, o simplemente ceremonial-internacionales- no tienen relevancia práctica alguna. 2) En el plano estrictamente teorético: a) o bien, el membrete «fundamentos» encubre unas cuestiones empíricas cuya averiguación corresponde a las ciencias sociales (psicología, sociología, politología, antropología y demás), y por tanto es confusionista entender referirse a tales investigaciones bajo dicho membrete; b) o bien, se trataría de señalar unas estructuras del pensamiento, sean de orden lógico o psicológico-empíricas, mas lo cierto es que en ninguna de estas dos esferas esos supuestos «fundamentos» se presentan como necesarios y ni siquiera como habituales. 3) En todo caso, es dable creer en tales o cuales «fundamentos» metafísicos; pero estos, sean cuales fueren, no son reconocibles mediante la razón laica, constituyen unos postulados de fe, solo elucidables en órdenes de pensamiento teológicos o cuasiteológicos ${ }^{4}$.

\footnotetext{
${ }^{4}$ Aclaro, por las dudas: No afirmo que las elucidaciones teológicas, sobre la materia que fuere, sean ilegítimas como tales; esto es, siempre y cuando no den a entender que son lo que
} 
no son. Dicho en términos de Wittgenstein: una cosa son los «juegos de lenguaje» teológicos, cuya «gramática» presupone necesariamente la aceptación de tales o cuales creencias exclusivamente religiosas, y otra cosa son cualesquiera juegos de lenguaje donde no se parta de tales presupuestos (o sea, donde estos mismos ni se afirman ni se niegan). En la medida en que al hablar de «derechos humanos» se reconozca que ese discurso está necesariamente basado en ciertas creencias religiosas, entonces sí es perfectamente legítimo hacerlo objeto de elucidaciones de tipo teológico. En cambio, si se pretende que tal discurso tiene validez incluso con independencia de aceptar o no dichas creencias, entonces el o los «fundamentos» invocados, aun aceptando que los haya, no pueden ser justificados por discursos de contenido teológico, o parateológico. Aquí no me he referido a los razonamientos francamente teológicos sobre derechos humanos, impugno los fundamentos criptolaicos en esta materia. 
$\triangle \quad$ DOXA 27 (2004) 